\title{
Research on Targeted Poverty Reduction through Tourism
}

\author{
Xiangmei Meng \\ Shandong College of Tourism \&Hospitality, Shandong 250200, China
}

Keywords: precision poverty alleviation; tourism; recommended measures

Abstract: Accurate poverty reduction was first proposed by Secretary Xi in 2013. The goal of this idea is to realize the common prosperity of our people. Today, most families in our country are no longer worried about the issue of food and clothing. However, in some remote mountainous areas, the issue of adequate food and clothing is still the top priority. For this situation, the task of poverty eradication is arduous, but there are challenges and opportunities. We cannot just see the poverty in the mountainous areas, we should also see the beautiful scenery and rich tourism resources of mountainous areas, and the Central Government has also issued documents on many occasions, which proposes to give full play to the role of rural tourism in poverty-stricken areas in driving poverty alleviation, and then this kind of policy will be promoted nationwide to achieve the precise assistance of tourism for poverty alleviation.

\section{Introduction}

Nowadays, the pressure on people's lives has increased, and the pace of life in the city has also accelerated. People have been unable to stand still. People's tranquility and stability that people miss more and want to escape from urban hustle and bustle, people will The use of holidays to relax in the scenic mountainous areas provides opportunities for the development of tourism in rural areas. In this environment, the poverty-stricken, poverty-stricken, precision-assisted tourism has emerged. This article will combine the actual situation and social development trends with the theory of sustainable development and the theory of precision poverty alleviation as the theoretical basis, and do a good job in some aspects of poverty alleviation in tourism. For example, Henan Song County, Pingyao Ancient Town, Hebei Province [1], Hebei Province Tangshan, Rucheng County, Shandong Province and other areas of analysis and discussion, summed up their successful experience, and use it to achieve the precise help of tourism poverty alleviation.

\section{Research Background and Significance}

\subsection{Research background}

No matter whether it is a developed country or a developing country, it is impossible to achieve prosperity for all people. Each country has some poor households. After China's reform and opening up, the poverty population has been greatly reduced, but there are also a small number of 
poor people living in mountainous areas [2]. Life, education, and medical care are still not guaranteed. Only if this part of the people is separated from the poverty, can China achieve a comprehensive well-to-do society.

The poverty-stricken people in China are mostly in the mountainous areas. Closed sources and rugged mountain roads have caused poverty today. However, mountainous areas are not without merit. For example, Henan Song County, Pingyao Ancient Town in Shanxi Province, Tangshan City [3], Hebei Province and other areas rely on their rich tourism resources to lift poverty. To get rich, the good development of tourism has not only promoted the construction of local roads, but also strengthened the links between the local people and the outside world. Various new knowledge and new things are known to all. The development of tourism has driven the development of all aspects of poverty-stricken areas. Fundamentally achieved precision assistance in tourism poverty alleviation [4].

\subsection{Research significance}

The theoretical foundation of tourism poverty alleviation precision assistance is the precision poverty alleviation carried out by our country. On the basis of it, we have expanded and made it more practical for tourism. However, our country's long-standing local poverty alleviation has always depended on local economic development to drive poverty. With the development of the masses, this method can indeed play a leading role in the implementation of the early stage, but it will appear that there is not enough stamina behind it. However, to carry out precision assistance, we must break this stagnant state and include people who are really difficult. Going to poverty alleviation actions, using them as key poverty alleviation targets, summing up and drawing on past experience, we will explore a road that is truly suitable for tourism in the poverty-stricken mountainous areas, and put it into practice [5].

In recent years, China's tourism assistance for poverty alleviation has achieved a certain degree of success. However, there are still some deficiencies. For example, in some regions, the phenomenon of the cart before the horse has turned upside down, and the gap between the rich and the poor has widened. There is also a lack of concrete proposals for measures. It is just a matter of verbally giving money. The point of precision assistance is on the word "precision." This is a targeted aid. This article will focus on this issue, and it will be put forward in the areas of precision tourism assistance for poverty alleviation and precision tourism assistance for poverty alleviation. Specific measures, and drawing on the classic cases at home and abroad, provide the theoretical basis for the country in the follow-up activities. At the same time, it also broke the deadlock faced by China in tourism management precision poverty alleviation and improved the accuracy of poverty alleviation in China.

\section{Research on Poverty Alleviation at Home and abroad}

\subsection{Domestic research on poverty alleviation}

In China, the prototype of precision tourism assistance for poverty alleviation in China is "farmland music". After rising to a national strategy in recent years, it gradually became better. However, overall, China's research on poverty alleviation in rural tourism is still not that Comprehensive, its main performance in the following aspects: First, China's rural tourism develops rapidly, there is no solid foundation, and the researchers studied rural tourism from different aspects, resulting in people's understanding of rural tourism is difficult to unify, It is not able to understand it well. Second, there are few successful cases. Most of them are full of stamina. The latter part is stagnant and does not lay a solid foundation for subsequent development. 
After the people were identified as poverty-stricken families, the poverty alleviation departments responsible for poverty alleviation were not strong enough. They often came to the poverty-stricken households during the holidays to express their sympathy. There were no specific measures to help them get rid of poverty, but they were just taking the form. Moreover, there is no reform of the residents' ideology. You cannot rely solely on the country to help you get rid of poverty. First of all, you must have a sense of getting out of poverty. The state is just a springboard for you to get rid of poverty, not your nanny, and it is precisely because the poor are unaware of it. This point, therefore, the problem of poverty has not been well resolved.

\subsection{Research on poverty reduction in foreign countries}

In foreign countries, on the contrary, foreign residents' private ownership and territorial possession are relatively strong. In some developing countries abroad, local residents are relatively excluded from rural tourism. They think that income is the second most important foreign tourists will undermine their original living environment. They have disrupted their original rhythm of life and affected their negative values. As a result, local residents have a negative attitude toward rural tourism and are reluctant to launch a rural tourism project. These emotions have greatly constrained the development of rural tourism.

\section{The Significance of Developing Tourism to Assist Poverty}

\subsection{Contributing to the change of the concept of the masses}

Now that the idea of "a good wine is not afraid of a deep alley" is outdated, good things are not well publicized and they lose their value. Beautiful scenery can not only be joyful to the body but also can exert its other values. For example, help the people get rich and give full play to its value. Abundant tourism resources have not been developed. Sometimes the concept of local residents is still in a relatively conservative state. They do not realize that rural tourism can make them get rich. Therefore, if you are afraid of being located in a mountainous area, you are afraid of not having advanced ideas. The arrival of tourists can not only promote economic development, but also bring about new things from the outside world. All these can bring about changes in the ideas of local residents. To broaden their horizons and renew their ideas is more conducive to the future work of tourism poverty alleviation.

\subsection{Helping the poor get out of poverty}

For a long period of time, people are accustomed to traditional forms of farming and have not dared to try other forms of labor. They have only a single source of living and have lagged behind in economic development. Local residents have lived on subsistence lines. Through the realization of tourism assistance for poverty alleviation and the development of innovative economic models, coupled with a series of comprehensive industries driven by tourism, it can effectively promote local economic development and enable the people to get rich at the doorstep.

\subsection{It is conducive to the unity and stability of society}

"Jun is a boat, people are water, and water can carry a boat and it can also overturn it." Most of the country's stability comes from the stability and prosperity of the people's lives. Therefore, the remaining poor people are also factors that affect the stability of our country. Accurate help for poverty alleviation can enable migrant workers to return to their hometowns to reduce the 
phenomenon of "left-behind children" and "empty netters". At the same time, it can also enable surplus labor to be employed twice and eliminate illegal activities such as playing mahjong and gambling. All these things are conducive to the maintenance of social stability and unity.

\section{Examples of Tourism Assistance in Poverty Relief}

\subsection{Shandong Rucheng county}

Yancheng County is located in Heze City, Shandong Province. A number of ancient celebrities, such as the hometown of Sun Yi, Li Di and Su You, are on this land. Before the precise assistance of tourism in poverty alleviation, the economic level of Luancheng County was backward. Tancheng County has flat terrain and a large area of plains. However, most of the soil is sandy soil, and the soil quality is not very good. The harvest of crops is not very good. Farmers are still traditional farming methods, and their living sources are relatively simple. At the same time, irrigation is also One big problem is that relying on food for the rest of the day can barely sustain life. There is no extra money to carry out the construction of spiritual civilization. The gap between the rich and the poor in the county town is obvious. With the rise of China's rural tourism industry, Luancheng County is one of the regions where China started to develop scenic tourist areas earlier. The local government also wants to develop tourism through its own beautiful scenery and important cultural history. The practice has been found to be very effective. It not only brought the beautiful scenery and moving history of Luancheng County to the world, but also won the recognition of the world. It was rated as a Grade 4A scenic spot and drove the local economic development and helped the local area. Residents have made a fortune and improved their quality of life. More importantly, poverty reduction through tourism has increased the rate of poverty alleviation.

The People's Government of Tancheng County has successively developed local scenic spots and historic sites, and successfully established the 4A class scenic spots in Leicheng County, Leize Lake, the hometown of Sun $\mathrm{Xi}$, and Yicheng Temple, and successively improved the scenic spots. Become a comprehensive scenic spot. Today, 1,160 farmhouses have been developed around Lucheng County. After the development of tourism, the income of local residents reached 10,000 yuan per capital. When the farmers only planted corn and peanuts in 2001, the per capital income was only 2000, a five-fold increase compared to the same period last year, can be described as an earth-shaking change. Since the beginning of the tourism assistance for poverty alleviation, the people of Rongcheng County have actively cooperated with the government and participated in tourism development, and have quickly reached the road to prosperity. By realizing the tourism assistance for poverty alleviation, not only has the local economy been developed, but also the quality of life of the local residents has been improved. Moreover, a new road has been explored for the accurate assistance of poverty-stricken mountainous areas in tourism poverty alleviation.

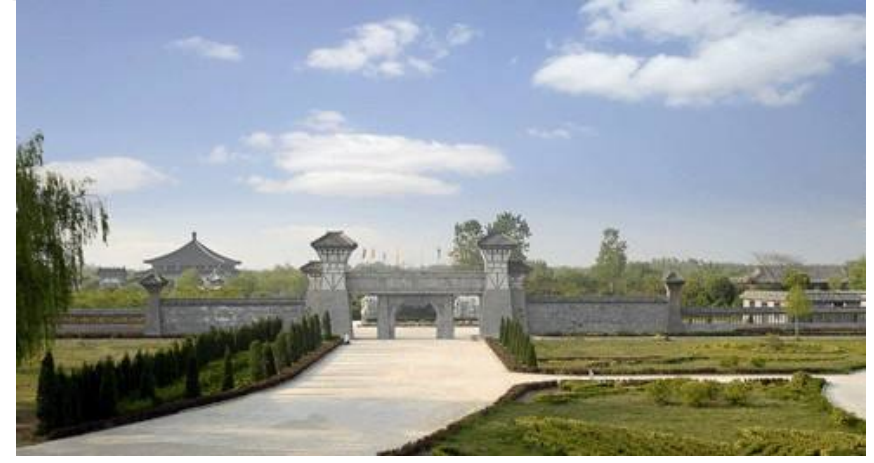

Fig. 1 Sunyang Tourism City Project in Tancheng County 


\subsection{Government leaders}

In Ji County, the county has 893,000 people, of which the urban population is 107,000 . Faced with this situation, the Fucheng County government has proposed to vigorously develop the tourism industry and let the tourism industry drive the strategic deployment of local economic development, establishing a set of "governments". Leaders, departments, and residents participated in the process, planning more than 50 preferential policies to help the development of rural tourism. Although Rucheng County is the government leader, it is not the dominant person, not the organizer, giving full play to the market's subjective initiative and creating a good investment environment.

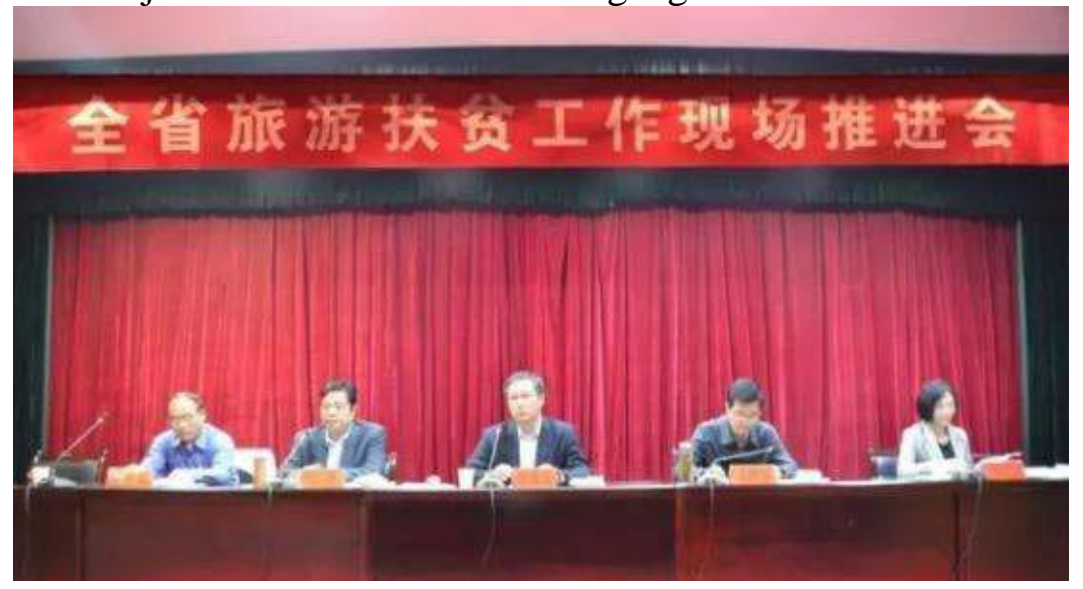

Fig. 2 Government reduces poverty through the development of tourism projects

\subsection{Strengthen infrastructure construction}

Due to the inconvenience of transportation in rural areas, the beautiful scenery and rich tourism resources in Luancheng County in 1990 "have been cultivated by people who are not well-known". Since the implementation of tourism assistance for poverty alleviation, the Yucheng County Government has vigorously carried out local infrastructure construction, extensively built highways, conducted multiple entrances and exits to scenic spots, built large-scale parking lots, standardized surrounding hotel management, built more toilets, and maintained Health, further improve the WIFI coverage, the best of these external conditions, and establish a good sense of tourism services.

\subsection{Characteristic marketing}

In order to raise the popularity of Luancheng County and open its market, the People's Government of Luancheng County took the lead in marketing. It just started to take steps to become smaller. Local media and reporters were invited to report to the city and the surrounding cities and provinces were promoted. However, it has achieved surprisingly good results and has been recognized by all levels of government. After that, Sun Yi Tourism City not only became a symbol of Luancheng County, but also became a famous tourist attraction in Shandong Province as a whole, and it became a national 4A-level scenic spot.

\subsection{Encourage the local residents to participate actively}

The biggest beneficiary group for the development of tourism-based poverty alleviation and precision assistance is the local people. Therefore, they need their active participation. We should vigorously nurture the enthusiasm of the local people and the ability to develop tourism so that the local people can truly feel the tourism. Poverty alleviation benefits to them. At the same time, they 
can also encourage them to make suggestions on tourism construction, put forward their own opinions, and truly participate in poverty alleviation. We can adopt shareholding, dividends at the end of the year and other policies to mobilize the enthusiasm of local residents.

\subsection{Pay attention to provide quality services}

Visitors to travel not only look at the scenery, but also the quality of service is also very important. Luancheng County pursues quality services, reflects the overall quality of the scenic area from the aspect of service, sets up tourist service points, transparently publicizes complaints calls, and has a The unified management of restaurants, hotels, and hotels eliminates fraud, blackmail, and other behaviors. If any discoveries criminalize their actions, they must ensure that the order of the resorts is unrestrained, the service is attentive, and the tourists have a perfect play experience. Reaching the satisfaction of tourists can also create a good reputation for us and serve two purposes.

\section{Conclusion}

The problem of poverty cannot be solved overnight. There are no hard targets in the poverty-stricken areas and there is a lack of industrial support. We can only find new ways to help them get out of poverty. This article starts with the status of the development of rural tourism, supports them with examples of precision assistance for tourism poverty alleviation, and finally analyzes the feasibility of policies from the long-term interests. All in all, tourism-based poverty alleviation assistance must overcome its eagerness for quick success and instant benefit. It should not only consider the immediate interests, but also pay more attention to long-term development. Tourism should not only be a tourist, and it should break the traditional mode of tourism thinking to help the poor. We must not only help the residents get rich. In addition, we must help the poor get out of poverty, build a tourism mechanism with self-development capacity, use scientific and rational poverty alleviation policies to achieve the goal of precision assistance, promote the development of tourism in poverty-stricken mountain areas, and make more rural areas lift off poverty. With better development, I believe that in the context of national poverty alleviation, fully mobilizing the enthusiasm of the residents will surely win the battle against poverty and achieve the goal of a well-to-do society in China as soon as possible.

\section{References}

[1] Deng Xiaohai, Zeng Liang,Luo Mingyi, et al.Research on the accurate identification of tourism poverty alleviation in the context of precision poverty alleviation.Ecological Economy,Vol. 31 (2015) No. 04, p. 94-98.

[2] Deng Xiaohai, et al. Exploring the Accurate Help for Poverty Alleviation by Tourism. Journal of Xinjiang University (Philosophy, Humanities and Social Sciences), Vol. 43 (2015) No. 06, p. 21-27.

[3] Kai Yan, et al. Community participation in tourism poverty alleviation research from the perspective of precision poverty alleviation--Based on the survey of Dali Shuanglang Village.Tourism Research, Vol. 9 (2017) No. 01, p. 74-82.

[4] Huang Yuyuan, et al. Predicament and path selection of precision poverty alleviation in rural tourism. Henan Normal University, 2017.

[5] Tian Cuicui, et al. Research on the Performance Evaluation of Tourism Preferential Poverty Alleviation in Naliang Village in High Mountains of Chongqing Based on Management Entropy. Southwest University, 2017. 